\title{
Dynamic testing of concrete under high confined pressure. Influence of saturation ratio and aggregate size
}

\author{
P. Forquin ${ }^{1, a}$, E. Piotrowska ${ }^{1}$, and G. Gary ${ }^{2}$ \\ ${ }^{1}$ Laboratoire Sols, Solides, Structures et Risques, Université Grenoble Alpes, BP. 53, 38041 Grenoble Cedex 9, France \\ ${ }^{2}$ Laboratoire de Mécanique des Solides, Ecole Polytechnique, 91128 Palaiseau, France
}

\begin{abstract}
Concrete structures can be exposed to intense pressure loadings such as projectile-impact or detonation near a concrete structural element. To investigate the mechanical behaviour of concrete under high confining pressure, dynamic quasi-oedometric compression tests have been performed with a large diameter $(80 \mathrm{~mm})$ Split Hopkinson Pressure Bar apparatus. The concrete sample is placed within a steel confining ring and compressed along its axial direction. Hydrostatic pressures as high as $800 \mathrm{MPa}$ and axial strain of about $-10 \%$ are reached during the tests. In the present work, experiments have been conducted on two types of concrete: MB50 microconcrete with a maximum grain size of $2 \mathrm{~mm}$ and R30A7 ordinary concrete of maximum grain size about $8 \mathrm{~mm}$. Both concretes are tested in dry or saturated conditions. According to these dynamic experiments it is noted that grain size has a small influence whereas water content has a strong effect on the confined behaviour of concrete.
\end{abstract}

\section{Introduction}

In many military and civil applications related to the safety of buildings or structures (power plants, headquarters, tanks of dangerous materials, dams... ), regarding accidental or intentional hazards such as ballistic impact, blasting, rock fall, plane crash or also earthquake, concrete can be exposed to extreme loading involving high hydrostatic pressure up to $1 \mathrm{GPa}$ and high strainrate levels (several hundreds of $1 / \mathrm{s}$ ) [1]. Under such loading conditions shear mechanisms and collapse of pores are observed. So the deviatoric strength (the deviatoric stress being defined as the difference between the maximal and the minimal principle stresses) and the compaction law of concrete need to be investigated taking into account the free water saturation ratio within the concrete. Quasi-oedometric compression test allows testing the mechanical response of the material under a quasi-uniaxial deformation loading path [2]. During a QOC (Quasi-Oedometric Compression) test, a cylindrical specimen tightly enclosed in a confinement vessel is axially compressed by means of high strength compression plugs (Fig. 1). As it tends to expand, both radial and axial stresses increase in the specimen. Thus, the test provides a reading of the strength of the material at different levels of pressure.

Several experimental set-ups have been proposed in the literature to perform quasi-oedometric compression tests. One may cite the experimental work performed by Burlion et al. [3] with steel confining ring. Dynamic tests have been conducted by Gatuingt [4] with confining cells made of steel or brass. A new analysis of experimental data was proposed by Forquin et al. [2,5], taking into account the shortening of the specimen and a possible plastic

\footnotetext{
${ }^{a}$ Corresponding author: pascal. forquin@3sr-grenoble.fr
}

deformation of the confining cell. This methodology was applied to dynamic QOC tests performed with a SplitHopkinson Pressure Bar device [6]. The accuracy of the method and the influence of friction were specially discussed.

In the present paper, the dynamic testing results obtained on an ordinary concrete (R30A7 concrete, max. grain size equal to $8 \mathrm{~mm}$ ) are compared to experimental data obtained with a MB50 microconcrete [7]. The concrete composition, the specimen size, the experimental procedure, the data processing and the results are detailed in the next parts.

\section{Experimental method and processing of data}

\subsection{Concrete composition}

Two types of concrete with very different mesostructures have been tested. On the one hand, the MB50 microconcrete, is characterized by a water to cement ratio of 0.5 and a maximum grain size of $2 \mathrm{~mm}$. The aggregate distribution is similar to a standard concrete but at a lower scale. On the other hand, the R30A7 concrete is closer to a standard concrete with siliceous aggregates up to $8 \mathrm{~mm}$ diameter and a water to cement ratio of 0.64 resulting in a compressive strength of about $30 \mathrm{MPa}[8,9]$. Four levels of free-water saturation ratio are considered in the present study in the case of R30A7 concrete: dry, 60\%, $80 \%, 100 \%$. The composition of each concrete is gathered in Table 1.

\subsection{Specimen size}

Different sample sizes are used for both concretes. The cylindrical samples of MB50 microconcrete were $29 \mathrm{~mm}$

This is an Open Access article distributed under the terms of the Creative Commons Attribution License 4.0, which permits unrestricted use, distribution, and reproduction in any medium, provided the original work is properly cited. 
Table 1. Composition of MB50 microconcrete and R30A7 concrete.

\begin{tabular}{|l|c|c|}
\hline Concrete & MB50 [7] & R30A7 [8,9] \\
\hline Aggregates $\left(\mathrm{kg} / \mathrm{m}^{3}\right)$ & 0 & 1008 \\
\hline Sand $\left(\mathrm{kg} / \mathrm{m}^{3}\right)$ & 1783 & 838 \\
\hline Cement $\left(\mathrm{kg} / \mathrm{m}^{3}\right)$ & 400 & 263 \\
\hline Water $\left(\mathrm{kg} / \mathrm{m}^{3}\right)$ & 200 & 169 \\
\hline Admixture $\left(\mathrm{kg} / \mathrm{m}^{3}\right)$ & 12 & 0 \\
\hline Water/Cement & 0.5 & 0.64 \\
\hline Maximum grain size $(\mathrm{mm})$ & 2 & 8 \\
\hline
\end{tabular}

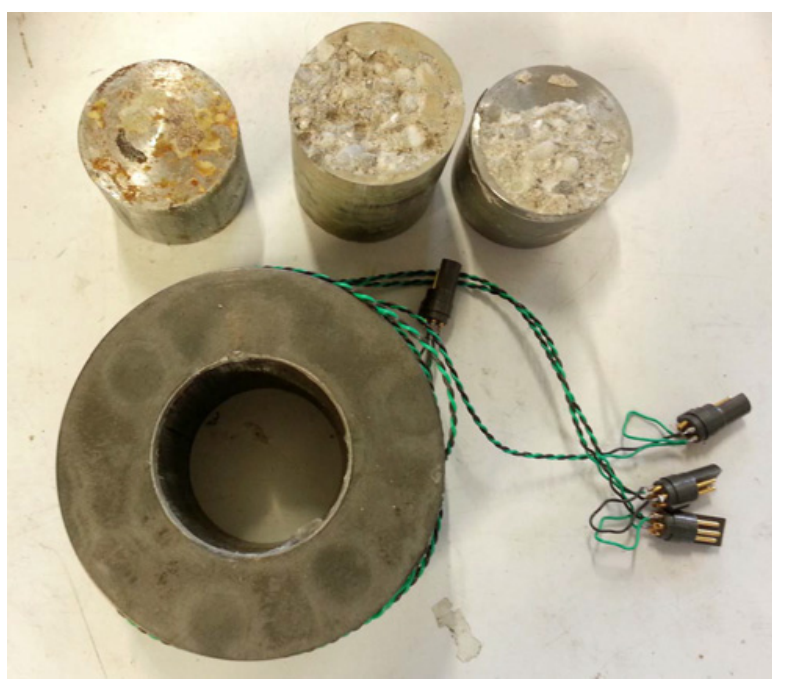

Figure 1. Steel confining ring, compression plugs and cylindrical sample used in a quasi-oedometric compression test.

in diameter and $40 \mathrm{~mm}$ in length and the steel confining ring was $60 \mathrm{~mm}$ in outer diameter and $45 \mathrm{~mm}$ long (Table 2) [7].

In the present work, the confining ring and the sample used for testing R30A7 concrete are larger ones. The cylindrical samples, $40 \mathrm{~mm}$ in diameter and $50 \mathrm{~mm}$ in length, are used. The confining ring made of high-strength steel (elastic limit of about $1800 \mathrm{MPa}$ ) is $40 \mathrm{~mm}$ in inner diameter, $80 \mathrm{~mm}$ in outer diameter and $60 \mathrm{~mm}$ long (Fig. 1, Table 2). The outer diameter of the ring is large enough to prevent any plastic strain within the ring for levels of internal pressure applied on the internal surface as high as $800 \mathrm{MPa}$. The length of the ring $(50 \mathrm{~mm})$, higher than that of the specimen, prevents the expulsion of the specimen from the ring during the test (especially in dynamic tests). The specimen is compressed by means of 2 cylindrical plugs (Fig. 1) made of high-strength steel (elastic limit of about $1800 \mathrm{MPa}$ ) allowing maximum axial stress level during the tests of about $1600 \mathrm{MPa}$. The steel plugs have the same diameter than the concrete specimens $(40 \mathrm{~mm})$ and are $30 \mathrm{~mm}$ long.

\subsection{Setting of the sample}

The R30A7 concrete specimens were machined in large blocks 40 days after the mix was poured into watertight plywood moulds. A special procedure was set to align the ring, the sample and the two plugs. First, the concrete sample is scotch taped to the upper plug. The concrete specimen is slowly introduced within the ring previously partially filled by a bi-components epoxy resin named "Chrysor ${ }^{\circledR}$ C6120" so this interface product is slowly extruded during this stage and the internal gap between the specimen and the ring is totally filled. 24 hours later, the Chrysor ${ }^{\circledR}$ product is hardened so the ring, the specimen and the two plugs can be safely handled.

\subsection{Dynamic testing facility}

The dynamic quasi-oedometric compression experiments have been conducted in the LMS laboratory with a large SHPB (Split Hopkinson Pressure Bar) facility. The SHPB system employed in this work and the processing method are detailed in [Forquin et al., 2008b]. It consists in a striker, an input bar and an output (transmitter) bar all made of steel bars (elastic limit $1200 \mathrm{MPa}$ ) with a diameter of $80 \mathrm{~mm}$. The striker, the input bar and the output bar are $2.2 \mathrm{~m}, 6 \mathrm{~m}$ and $4 \mathrm{~m}$ long, respectively. A so-called pulseshaper technique is used to increase the rising time of the loading force and to ensure correct stress equilibrium in the interesting part of the experiment. For this purpose a thin disk of lead is placed on the impact end of the incident bar. As long as the lead is not totally flattened, the maximum stress induced by the striker is not reached.

\subsection{Processing method}

Since our specimen is located between the two plugs, and not directly sandwiched between the input and transmitter bars, forces and velocities have to be calculated at the faces of the specimen. Their calculation is based on the analysis of the wave propagations in a bar with non-constant acoustic impedance [10-12]. Knowing the basic waves, the waves at specimen faces are computed, allowing for the calculations of forces and displacements at compression plugs-specimen interfaces. Input and output forces provide the axial stress $\bar{\sigma}_{z z}^{S}$ in the sample whereas the axial strain $\varepsilon_{z z}^{S}$ is deduced from the axial displacements at both ends of the sample.

Furthermore, strain-gauges glued on the ring provide the circumferential (hoop) strain used to estimate the level of internal radial stress $\bar{\sigma}_{r r}^{S}$ and strain $\varepsilon_{r r}^{S}$ within the specimen according to the data processing proposed by $[2,6,7]$. In particular, the calculation of the mean radial stress $\bar{\sigma}_{r r}^{S}$ within the specimen is calculated as function of the external hoop strain $\varepsilon_{\theta \theta}^{(z=0)}$, the shortening of the specimen (of length $h$ ) deduced by the axial strain, and the defect of symmetry $\left(\delta_{z}\right)$ that could result from an initial imperfect positioning or a slip of the specimen inside the ring during the test.

$$
\bar{\sigma}_{r r}^{S}=\left(P_{\sigma}(h)+Q_{\sigma}(h) \times\left(\delta_{z}\right)^{2}\right) \varepsilon_{\theta \theta}^{(z=0)}
$$

where $P_{\sigma}$ and $Q_{\sigma}$ are two polynomial functions of degree 2, which coefficients have been identified for the considered cell from numerical simulations considering a range of $h(45$ to $50 \mathrm{~mm})$ and $\delta_{z}(0$ to $3 \mathrm{~mm})$. The axial stress and radial stress being calculated, it is possible to evaluate the average deviatoric stress:

$$
\bar{\sigma}_{\text {deviatoric }}^{S}=\left|\bar{\sigma}_{z z}^{S}-\bar{\sigma}_{r r}^{S}\right|
$$


Table 2. Dimensions of samples and steel ring used in previous work and present work.

\begin{tabular}{|l|l|l|}
\hline Experiments & {$[7]$} & Present study \\
\hline Concrete, max. grain size & MB50, 2 mm & R30A7, 8 mm \\
\hline Sample: Diameter $\times$ length $(\mathrm{mm})$ & $29 \times 40$ & $40 \times 50$ \\
\hline Steel ring: Outer diameter $\times$ length $(\mathrm{mm})$ & $60 \times 45$ & $80 \times 60$ \\
\hline
\end{tabular}



Figure 2. Diagram of SHPB device and dynamic testing facility used in LMS laboratory.
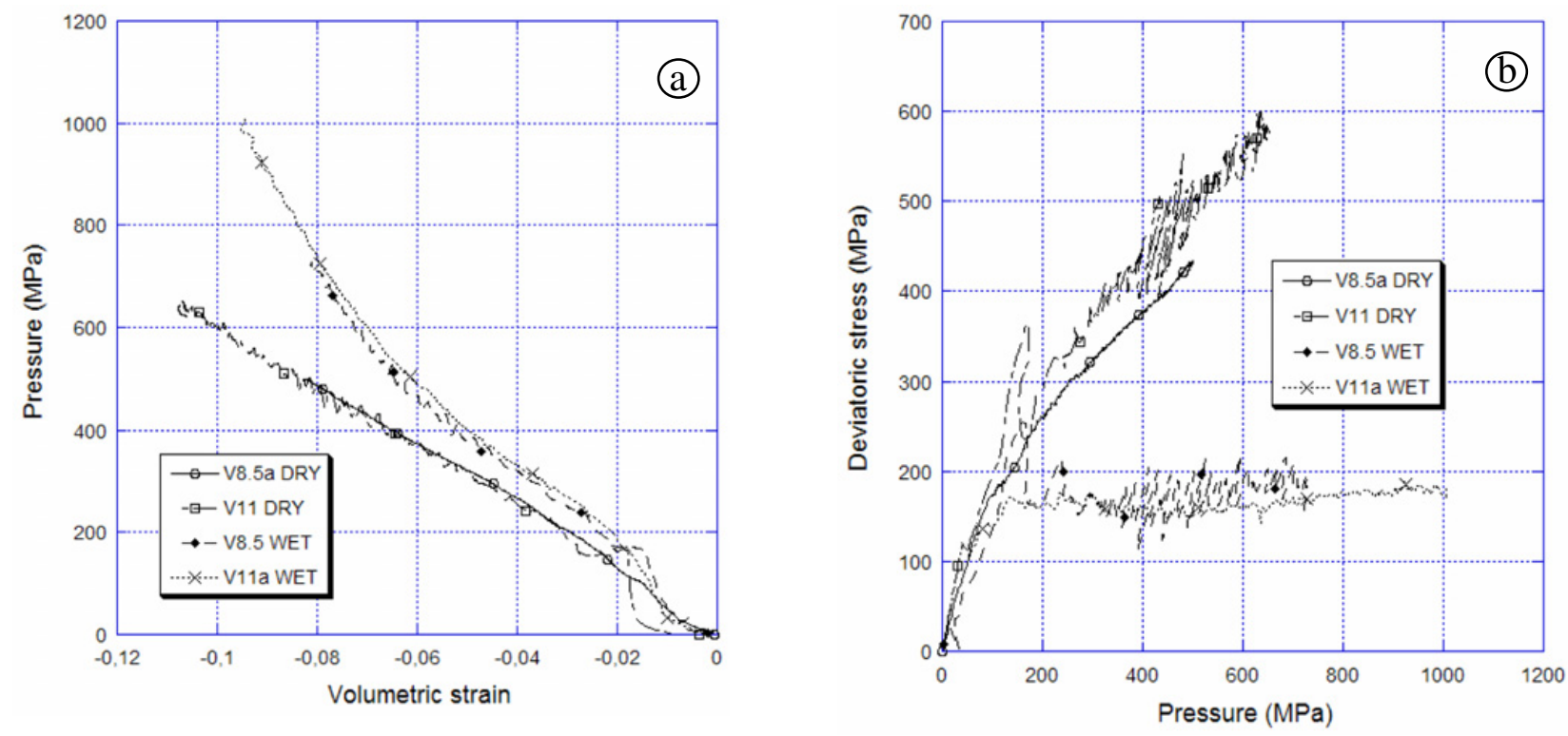

Figure 3. Dynamic tests performed on dried and wet microconcrete (Tests V8.5: strain rate $=90 / \mathrm{s}$, Test V11: strain rate $=150 / \mathrm{s}$ ) [Forquin et al., 2010]: (a) Compaction curve and (b) Deviatoric behaviour.

as well as the average hydrostatic pressure and the volumetric strain according to the formulas:

$$
\begin{gathered}
\bar{P}_{\text {hydrostatic }}^{S}=-\frac{1}{3}\left(\bar{\sigma}_{z z}^{S}-2 \bar{\sigma}_{r r}^{S}\right) \\
\bar{\varepsilon}_{\text {volumetric }}^{S}=\left(1+\varepsilon_{z z}^{S}\right)\left(1+\varepsilon_{r r}^{S}\right)^{2}-1 .
\end{gathered}
$$

Then the deviatoric stress can be plotted as function of the hydrostatic pressure (deviatoric behaviour) and the hydrostatic pressure can be plotted as function of the volumetric strain (hydrostatic behaviour).

\section{Dynamic experiments performed on MB50 microconcrete [7]}

The confined behaviour of dry and wet (water-saturated) microconcrete was investigated by Forquin et al., [7] with the testing facility and experimental procedure described in the part 2. The change of deviatoric stress is plotted as function of the hydrostatic pressure (Fig. 3b) and the hydrostatic pressure is plotted as function of the volumetric strain (Fig. 3a). First, the hydrostatic response of wet microconcrete is stiffer than the one of dry microconcrete (Fig. 3a). Moreover, the deviatoric strength of wet microconcrete is not exceeding about $200 \mathrm{MPa}$ even under hydrostatic pressure as high as $1000 \mathrm{MPa}$ 


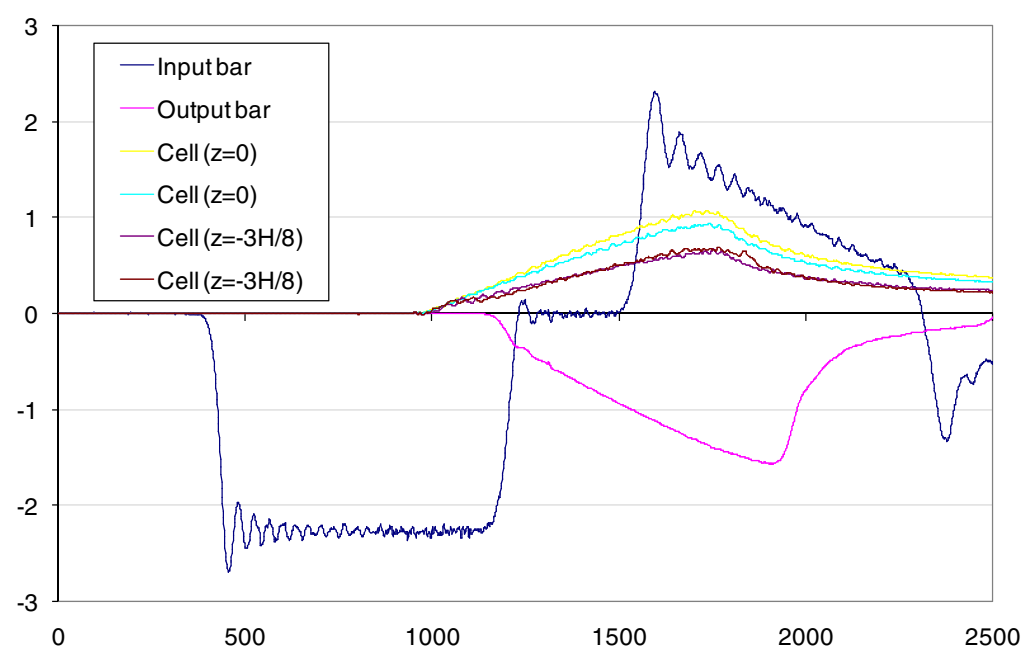

Figure 4. Dynamic experiments performed on R30A7 concrete with the SHPB facility. Blue curve: incident and reflected pulse, pink curve: transmitted pulse (strain-rate of about 100/s).
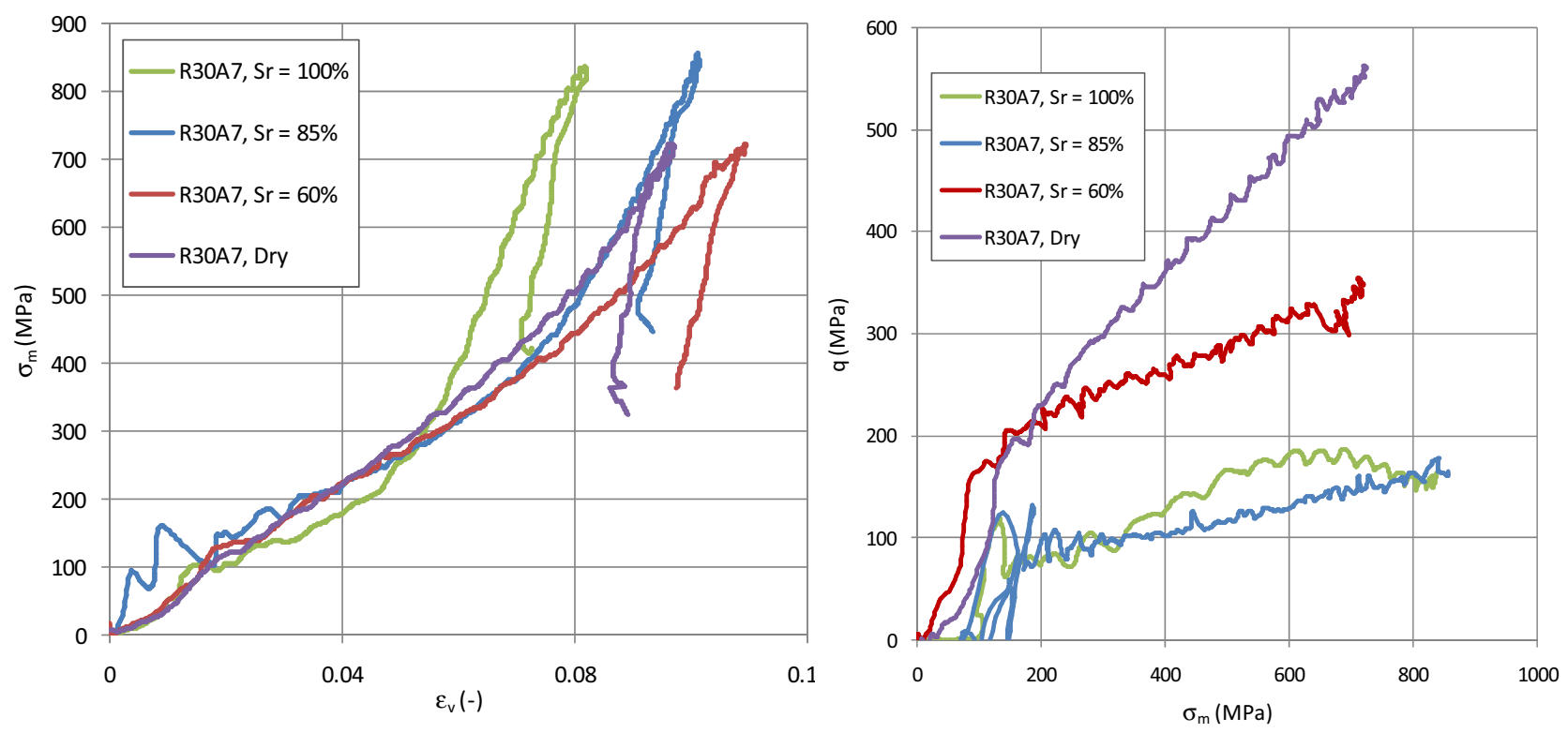

Figure 5. Dynamic quasi-oedometric experiments performed on wet R30A7 concrete: (a) Compaction curve and (b) Deviatoric behaviour.

(Fig. 3b). On the other hand, dry microconcrete exhibits a deviatoric strength continuously increasing with the increase of pressure (Fig. 3b). As explained by [7,9], the limited strength in saturated concrete is due to an increase of pore-pressure within the microstructure.

\section{Results of dynamic experiments performed on wet R30A7 concrete}

The confined behaviour of R30A7 concrete was investigated with the testing facility and experimental procedure described in the part 2 considering four different saturation ratios (dry concrete, $60 \%, 80 \%, 100 \%$ ). As mentioned in the part 2, larger cylindrical samples $(40 \mathrm{~mm}$ in diameter and $50 \mathrm{~mm}$ in length) and confining ring $(80 \mathrm{~mm}$ in outer diameter and $60 \mathrm{~mm}$ long) are used than with microconcrete. An example of experimental data (strain gage on the input bar, strain gage on the output bar and strain gages on the confining cell) obtained with a dry sample is given in Fig. 4.

Figure 5 illustrates the dynamic response of R30A7 concrete samples considering four saturation ratios (dry concrete, $60 \%, 80 \%, 100 \%$ ). Similarly to what has been observed with microconcrete, both hydrostatic and deviatoric responses are strongly influenced by the water content. In particular, the deviatoric strength of wet concrete is not exceeding $200 \mathrm{MPa}$ even under the maximum hydrostatic pressure reached during the test: $800 \mathrm{MPa}$. On the other hand, dry concrete shows a continuous increase of strength with hydrostatic pressure, up to $550 \mathrm{MPa}$ at $700 \mathrm{MPa}$ of hydrostatic pressure (Fig. 5b). In addition, the hydrostatic response of saturated concrete is much stiffer than that of concrete with lower saturation degrees (Fig. 5a).

Finally, it is observed that the both dynamic hydrostatic and deviatoric responses of R30A7 concrete are very 
similar to the ones of MB50 microconcrete whatever the water content (dry or saturated). It confirms that the dynamic behaviour of concrete at high level of confinement is primarily a question of free water content rather than an effect of aggregate size.

\section{Conclusion}

Dynamic quasi-oedometric compression tests have been conducted on R30A7 ordinary concrete (maximum aggregate size: $8 \mathrm{~mm}$ ) and MB50 microconcrete (maximum aggregate size: $2 \mathrm{~mm}$ ) to investigate their mechanical response under high levels of pressure at high strainrates. The experimental procedure allows evaluating the hydrostatic behaviour (compaction curve) and deviatoric strength under pressure levels up to $800 \mathrm{MPa}$. The experimental results have shown a major influence of free water content on the confined behaviour of both concretes. The wet or saturated concretes exhibit stiffer hydrostatic response than dry concrete. Moreover their deviatoric strength is weaker than in dry concrete. Finally, the present study confirms the importance to take into account the free-water content in concrete to correctly investigate the mechanical response of concrete structures exposed to intense pressure loadings such as projectileimpact or detonation near a concrete structural element.

This research has been performed with the financial support of the CEA: French Alternative Energies and Atomic Energy Commission (Commissariat à l'énergie atomique et aux énergies alternatives). We would like to thank Dr. Eric Buzaud and Dr. Christophe Pontiroli (CEA- Centre de Gramat) for their sound technical and scientific advices. SHPB dynamic experiments have been performed in the LMS (Laboratoire de Mécanique des Solides, Palaiseau, France). The authors want to deeply thank Philippe Chevallier for its technical support, and Prof. Patrick Le Tallec, director of the LMS, for the warm welcome.

\section{References}

[1] P. Forquin, A. Arias, R. Zaera., R., 2008a. Int. J. Impact Eng. 35 (3), 133-146.

[2] P. Forquin, A. Arias, R. Zaera., 2007. Int. J. Solids Struct. 44, 4291-317.

[3] N. Burlion, G.Pijaudier-Cabot, N. Dahan, 2001. Int. J. Numer. Anal. Meth. Geomec. 25, 467-1486.

[4] F. Gatuingt, Ph.D. thesis, ENS Cachan, 1999.

[5] P. Forquin, A. Arias, R. Zaera. Experimental Mechanics 49, pp. 613-625, 2009.

[6] P. Forquin, G. Gary, F. Gatuingt, 2008b. Int J Imp Eng. 35(6), 425-446.

[7] P. Forquin, K. Safa, G. Gary, 2010. Cement Concrete Res. 40(2), 321-333.

[8] T. Gabet, Y. Malécot, L. Daudeville, 2008. Cem. Conc. Res. 38, 403-412.

[9] X.H. Vu, Y. Malécot, L. Daudeville, E. Buzaud, 2009. Int J Solids Struct. 46, 1105-1120.

[10] B. Lundberg, J. Carlsson, K. G. Sundin, 1990. J Sound and Vibration. 137(3), 483-493.

[11] G. Bacon, J. Carlsson, J.L. Lataillade, 1991. J of Phys IV. 1, 395-402.

[12] G. Gary, 2005. DAVID, instructions manual, Palaiseau, France. (http: //www . Ims . polytechnique. fr/EQUIPE/dynamique/index.html) 